\title{
Impact of COVID-19 on Dentistry
}

\author{
Minal M Kshirsagar ${ }^{1}$, Arun S Dodamani ${ }^{2}$, Rahul N Deokar ${ }^{3}$, Yogesh Garg ${ }^{4}$, Vrushali R Khobragade ${ }^{5}$, Kamal Garg ${ }^{6}$
}

\begin{abstract}
Pandemic situations always impose devastating aftereffects on communities and cause chronic damaging effects on the healthcare system. Novel coronavirus disese-2019 (COVID-19) which has originated in China (Wuhan) is nowadays an emerging threat to public health across the world. It is spreading worldwide so rapidly and has started infecting people in all possible ways. Several dental care facilities in affected countries are completely closed or have been only providing minimal treatment for emergency cases since the whole lockdown has been announced. However, in some affected countries, they are still providing regular dental treatment. This discrepancy could be because of the dearth of proper awareness, knowledge, protocol, or guidelines.
\end{abstract}

Keywords: COVID-19, Dentistry, Novel coronavirus.

International Journal of Clinical Pediatric Dentistry (2021): 10.5005/jp-journals-10005-2025

\section{INTRODUCTION}

Coronavirus disese-2019 (COVID-19) started in December 2019, sort of a viral outbreak in Wuhan city of central Hubei province of China. ${ }^{1,2}$ After observing the conditions of countries' health systems and the spread of the virus, WHO declared it a Public Health Emergency of International Concern on January 30, 2020. So far deaths in China are increasing; on 2nd February, the first death which was reported outside China was of a person from China (Wuhan) within the Philippines. WHO announced a name for the new coronavirus disease. On 11th February, COVID-19 since then has started affecting many countries enormously? With reference to the virus itself, the International Committee on Taxonomy of Viruses has renamed the former for the present named 2019-nCoV as severe acute respiratory syndrome coronavirus-2 (SARS-CoV-2). ${ }^{3}$ The whole world has got affected and responding by all possible ways such as social distancing, complete lockdown, and quarantine of suspected cases but healthcare providers are at the frontline during this fight against COVID-19. ${ }^{4}$ It is important to acknowledge healthcare workers are often already resilient and experienced in handling difficult circumstances but will need additional system orientated supports to cut back their burden. ${ }^{5}$

ADA on March 16, 2020, stated it was deeply concerned for the health and well-being of the public and the dental team as well. ADA recommends nationwide dentists should postpone elective procedures for the next 3 weeks to mitigate the spread of COVID-19. Concentrating on emergency dental care will allow us to care for our emergency patients and alleviate the burden that dental emergencies would place on hospital emergency departments. ${ }^{6}$

\section{Characteristics of 2019 Novel Coronavirus}

Coronaviruses (CoV) are single-stranded RNA viruses (+ssRNA) having a total of 39 species and a spike glycoprotein on the envelope; ${ }^{7}$ under the broad realm of Riboviria ${ }^{8}$ and so named because of the outer fringe of envelope proteins resembling crown ("corona" in Latin). This virus is further subdivided into four genera; alpha, beta, gamma, and delta. ${ }^{9}$ Previous literature suggests they are generally pathogenic to mammals and birds which affect upper
${ }^{1}$ Department of Public Health Dentistry, Nair Hospital and Dental College, Mumbai, Maharashtra, India

${ }^{2}$ Department of Public Health Dentistry, ACPM Dental College, Dhule, Maharashtra, India

${ }^{3}$ Department of Public Health Dentistry, SMBT Dental College and Hospital, Igatpuri, Maharashtra, India

${ }^{4}$ Department of Public Health Dentistry, Surendera Dental College and Research Institute, Sriganganagar, Rajasthan, India

${ }^{5}$ VYWS Dental College and Hospital, Amaravati, Andhra Pradesh, India ${ }^{6}$ Department of Periodontics, Surendera Dental College and Research Institute, Sriganganagar, Rajasthan, India

Corresponding Author: Minal M Kshirsagar, Department of Public Health Dentistry, Nair Hospital and Dental College, Mumbai, Maharashtra, India, Phone: +91 7066584979, e-mail: minalk115@ gmail.com

How to cite this article: Kshirsagar MM, Dodamani AS, Deokar $\mathrm{RN}$, et al. Impact of COVID-19 on Dentistry. Int J Clin Pediatr Dent 2021;14(5):711-714.

Source of support: Nil

Conflict of interest: None

respiratory tract infections in humans in a mild form. ${ }^{1}$ Currently, there are four genera of coronaviruses: $a \mathrm{CoV}, \beta-\mathrm{CoV}, \gamma-\mathrm{CoV}$, and $\delta$-CoV. Also, most of the coronavirus might be the reason behind infectious diseases in humans and vertebrates as well. The a-CoV and $\beta$-CoV predominantly affect humans and mammals on respiratory, gastrointestinal, and central nervous systems, whereas $\gamma$-CoV and $\delta$-CoV affect the birds mainly. ${ }^{10}$

\section{Dentistry-global Scenario}

We all are very well aware of occupational hazards in dentistry, such as hepatitis B and C, and relative risks. ${ }^{11}$ The possibility of a dental professional being positive for COVID-19 and infecting patients potentially must not be underestimated. ${ }^{12}$ It has come into view with a difficult task to the healthcare system including dentistry; as the primary route for spread is said to be by droplet transmission, during coughing, sneezing, and contact with fomites additionally. ${ }^{13,14}$ However, there are legitimate concerns with respect to aerosol 
transmission generated while talking, breathing, etc. In few cases, feco-oral transmission has also been reported with viral isolation from the feces of some patients. ${ }^{15,16}$ Most of the countries including India are using measures like complete lockdown and quarantine of positive and suspected cases. Routine attention to dental care has been terminated in most of the countries after complete lockdown. Oral healthcare providers are treating emergency dental cases with strict use of protocols and guidelines like the use of personal protection equipment (PPE). So many countries then quickly started to take measures to reduce cases into the community; they started quarantined positive and suspected cases to prevent possible transmission between known cases and local population; selfisolation, social distancing, and heightened hygiene. ${ }^{17}$ The New York Times brought to the notice of the world globe that dentistry had the foremost risk out of many professions with respect to COVID$19 .^{18}$ There have been literature available stating dental healthcare professionals to be at high risk of COVID-19 infection due to the close face-to-face contact with patients. ${ }^{10}$ Guo et al. conducted a study aimed to assess how the present COVID-19 epidemic influenced peoples' utilization patterns of emergency dental services in Beijing, China and reported that within the limitation of the study, the COVID-19 epidemic had a powerful influence on the employment of emergency dental healthcare services. ${ }^{19}$

\section{Aerosols and Splatter in Dentistry: INEVITABLE}

The best potential routes for the spread of COVID-19 infection in dental practice are direct contact with body fluids, environmental surfaces, or used instruments of an infected patient. The terms "aerosol" and "splatter" in dentistry were applied by Micik et al. in their initial work on aerobiology. ${ }^{20}$ Aerosols are known to be particles $<50 \mu \mathrm{m}$ in diameter. Particles of this size are tiny enough to be present in the air for an extended period before they get settled on surfaces. The smaller particles of an aerosol $(0.5-10 \mu \mathrm{m}$ in diameter) can penetrate and sustain the smaller passages of the lungs. The production of aerosols during dental procedures can affect dentists, teammates, and patients as well. An aerosol is a cloud of particulate and fluid which is usually evident during procedures like tooth preparation with a rotary instrument or air abrasion, use of an air-water syringe, employment of an ultrasonic scaler, or through air polishing. Each patient and site of operation may affect the contents of aerosol. However, it is practicable to assume that elements of saliva, nasopharyngeal secretions, plaque, blood, tooth components, and any material incorporated in the dental procedure, such as abrasives for air polishing and air abrasion, all are present in dental aerosols. There is moderate literature that pre-procedural oral rinses remarkably lowers the number of microorganisms in the dental aerosol. ${ }^{21}$

Micik et al. defined splatter as airborne particles larger than 50 $\mu \mathrm{m}$ in diameter and they behaved in an exceedingly ballistic way. These particles are large to become suspended within the air and are airborne only briefly.

\section{Dental Treatment during this Pandemic}

Despite the spread on large-scale of COVID-19 during this pandemic; it was seen that demand for urgent dental treatment decreased by $38 \%$ only; ${ }^{19}$ which certainly means that the public still needs urgent dental care even during this pandemic. The dental association's around the world are still varying from advising practitioners to shut their practices to reduce the number of routine check-ups; ${ }^{22,23}$ to no advice to any respect from several dental associations around the world. ${ }^{24}$ Closing dental care facility may burden afterward on dental care emergency services. It has been an extended time since dental education had to accelerate training and produce competent dentists in less time to combat this pandemic. The experience with the COVID-19 pandemic should prompt the Commission on Dental Accreditation and also the dental education community to heed the implications of a lock-step, time-based approach to training and consider how dentists are often prepared for crises like this and educated to a type of care that's not tied to the calendar but to performance. ${ }^{25}$

\section{Treatment Categorization}

Patients should be categorized and treated accordingly. It should be:

- Emergency management life-threatening conditions.

- Minimally invasive procedures if requires; without generation of aerosols.

- Emergencies need to be handled with invasive and/or aerosolgenerating procedures.

- Non-emergency procedures.

- Elective procedures.

\section{Triaging and Referrals}

Patients under investigation (PUI) are defined as patients who are having fever or acute respiratory infection (sudden onset with shortness of breath, cough, or sore throat) and traveled to or lived in affected countries or have direct contact with a confirmed/ suspected case of COVID-19 within 14 days before getting infected. ${ }^{26,27}$ All these patients should be provided with hand sanitizers, surgical masks, gloves if not possible they should be directed to cover their nose and mouth during talking, sneezing, coughing to avoid the risk of spread. All such PUls should be referred to nearby hospitals or quarantine centers and a list of such people should be updated regularly. They should not be allowed for public or private transport instead local District Health Offices should be contacted to arrange transports for them ${ }^{26}$ which later on can be disinfected.

\section{Telemedicine}

Over the last few years, there is potential improvement in the survival rate of cases suffering from critical oral disorders and this is possible due to early diagnosis and prompt treatment ${ }^{28,29}$ which is the most effective way of reducing the individual burden of the disease, decreasing morbidity, and mortality eventually improving quality of life. But how to do it in the pandemic. Telemedicine has gained more focus in this pandemic. Electronic consultations have gained even more visibility to take care with least in-person/direct contact with people to prevent the spread. ${ }^{30,31}$ It also helps patients to control chronic diseases by providing an early diagnosis. Telemedicine can also "forward triage" people with possible symptoms. This approach allows patients to be potentially screened and avoid the spread of the infection among patients, health professionals, and the community eventually. ${ }^{32,33}$ 


\section{Treatment Considerations}

- Anti-retraction dental handpiece with specially designed anti-retractive valves or other anti-reflux designs are strongly recommended as an extra preventive measure for crossinfection. $^{10}$

- Disposable materials and instruments should be used to minimize cross-infection. There is now unchallenged justification that careful constancy to hand hygiene lowers the quantity of possibility of cross-transmission of infections. ${ }^{34}$

- In case of pharmacological management of pain, avoid prescribing ibuprofen in suspected/confirmed cases of COVID$19 .^{30,35}$

- Intraoral imaging should be restricted to reduce the excessive salivation and gag reflex and extraoral radiographs should be utilized. $^{24,33}$

- Limit the treatment to minimally invasive procedures to the most.

- Proper management of medical and domestic waste generated by treatments of suspected/confirmed cases of COVID-19.

- The use of a rubber dam can be the best possible way to avoid the spread of infection and the success of the treatment. ${ }^{36-39}$

- Special precautions to be taken while performing aerosolgenerated procedures. ${ }^{15}$

- The use of the four-handed technique can be beneficial for controlling infection, also saliva ejectors with low or high volume can reduce the production of droplets and aerosols. ${ }^{40}$

- Previous literature suggests that viruses may survive in surgical smoke which is created by electrosurgical instruments; so special precautions to be taken for the management of surgical patients. $^{41}$

- The use of antiseptic oral rinses like povidone-iodine before the start of treatment in patients can reduce the viral load in saliva. ${ }^{42}$

- Patients taking antiviral drugs for COVID-19 should be frequently advised to monitor for hematological parameters, serum electrolytes, blood glucose, hepatic, and renal functions. ${ }^{43}$

\section{CONCLUSION}

COVID-19 has challenged healthcare systems and healthcare professionals in a way. The role of oral healthcare professionals is critically important. In the oral healthcare sector, additional training for the improvement of health or simulations regarding infection control should be emphasized as putting themselves at unnecessary risk is morally unacceptable. Uniform protocols and guidelines should be followed for the prevention of this virus. So in addition to the routine use of standard barriers like the use of masks and gloves, use of preoperative rinses and high-volume evacuation is recommended.

\section{References}

1. Roy D, Tripathya S, Kara SK, et al. Study of knowledge, attitude, anxiety \& perceived mental healthcare need in Indian population during COVID-19 pandemic. Asian J Psychi 2020;51:1-7. DOI: 10.1016/j. ajp.2020.102083.

2. Huang C, Wang Y, Li X, et al. Clinical features of patients infected with 2019 novel coronavirus in Wuhan, China. Lancet 2020;395(10223):497506. DOI: 10.1016/S0140-6736(20)30183-5.

3. Lai C-C, Shih T-P, Ko W-C, et al. Severe acute respiratory syndrome coronavirus 2 (SARS-CoV-2) and coronavirus disease-2019 (COVID-19): the epidemic and the challenges. Int J Antimicro Agen 2020;55(3):1-9. DOI: 10.1016/j.ijantimicag.2020.105924.

4. Bali RK, Chaudhary K. Maxillofacial surgery and COVID-19, the pandemic!!. J Maxillofac Oral Surg 2020(2). DOI: 10.1007/s12663-02001361-8.

5. Wilson AN, Ravaldi C, Scoullar MJL, et al. Caring for the carers: ensuring the provision of quality maternity care during a global pandemic. Women Birth 2021;34(3):206-209. DOI: 10.1016/j.wombi.2020.03.011.

6. Halepas S, Ferneini EM. A pinch of prevention is worth a pound of cure: proactive dentistry in the wake of COVID-19. J Oral Maxillofac Surg 2020;78(6):860-861. DOI: 10.1016/j.joms.2020.03.036.

7. Singh A, Shaikh A, Singh R, et al. COVID-19: from bench to bed side. Diabetes Metabol Syndr: Clin Res Rev 2020;14(4):277-281. DOI: 10.2147/PPA.S251812.

8. Vellingiri B, Jayaramayya K, lyer M. COVID-19: a promising cure for the global panic. Sci Total Environ 2020;725:138277. DOI: 10.1016/j. scitotenv.2020.138277.

9. Biswasa A, Bhattacharjeea U, Chakrabartia AK, et al. Emergence of novel coronavirus and COVID-19: whether to stay or die out? Crit Rev Microbiol 2020(2):1-12. DOI: 10.1080/1040841X.2020.1739001.

10. Peng $X, X u X, L i Y$, et al. Transmission routes of 2019-nCoV and controls in dental practice. Int J Oral Sci 2020;12(1):9. DOI: 10.1038/s41368-0200075-9.

11. Moodley R, Naidoo S, Wyk JV. The prevalence of occupational health related problems in dentistry: a review of the literature. J Occup Health 2018;60(2):111-125. DOI: 10.1539/joh.17-0188-RA.

12. Dave M, Seoudi N, Coulthard P. Urgent dental care for patients during the COVID-19 pandemic. Lancet 2020;395(10232):1257. DOI: 10.1016/ S0140-6736(20)30806-0.

13. Gupta N, Agrawal S, Ish P, et al. Clinical and epidemiologic profile of the initial COVID-19 patients at a tertiary care centre in India. Monaldi Arch Chest Dis 2020;90(1294):193-196. DOI: 10.4081/ monaldi.2020.1294.

14. Banerjee AK, Arora N. Coronavirus disease (COVID-19) pandemic: a race against time. Curr Top Med Chem 2020;20(16):1-4. DOI: 10.2174 /1568026620999200413145654.

15. Udwadia ZF, Raju RS. How to protect the protectors: 10 lessons to learn for doctors fighting the COVID-19 coronavirus. Med J Armed For India 2020;76(2):128-131. DOI: 10.1016/j.mjafi.2020.03.009.

16. Wu D, Wu T, Liu Q, et al. The SARS-CoV-2 outbreak: what we know. Int J Infect Dis 2020;94:44-48. DOI: 10.1016/j.ijid.2020.03.004.

17. Coulthard P. Dentistry and coronavirus (COVID-19) - moral decisionmaking. Br Dent J 2020;228(7):503-505. DOI: 10.1038/s41415-0201482-1.

18. The workers who face the greatest coronavirus risk. The New York Times (New York) 2020 March 15. available from https://www.nytimes. com/interactive/2020/03/15/business/economy/coronavirus-workerrisk.html.

19. Guo H, Zhou Y, Liu X, et al. The impact of the COVID-19 epidemic on the utilization of emergency dental services. J Dent Sci 2020;15(4):564567. DOI: 10.1016/j.jds.2020.02.002.

20. Harrel SK, Molinari J. Aerosols and splatter in dentistry a brief review of the literature and infection control implications. JADA 2004;135(4):429-437. DOI: 10.14219/jada.archive.2004.0207.

21. Marui VC, Silveira Souto ML, Rovai ES, et al. Efficacy of preprocedural mouthrinses in the reduction of microorganisms in aerosol. JADA 2019;150(12):1015-1026e. DOI: 10.1016/j.adaj.2019.06.024.

22. CDA, Dental Office Closure Due to COVID-19. 2020 available from https://www.cda.org/Portals/0/cda-covid19-dental-280officeclosure.pdf.

23. Scottish Government. Updated guidance for dental practices 2020 available from https://www.gdc-uk.org/docs/default-source/360 covid-19/ocdo-scotland-letter.pdf.

24. Alharbi A, Alharbi S, Alqaidi S. Guidelines for dental care provision during the 5 COVID-19 pandemic. Saudi Dent J 2020;32(4):181-186. DOI: 10.1016/j.sdentj.2020.04.001.

25. Casamassimo PS, Townsend JA. Pediatric dentistry during and after COVID-19. Pediat Dentis 2020;42(2):87-90. 
26. Ambigapathy S, Rajahram GS, Shamsudin UK, et al. How should frontline general practitioners use personal protective equipment (PPE)? Malays Fam Physician 2020;15(1):1-5.

27. Ministry of Health Malaysia, COVID-19 Management Guidelines [internet]. Malaysia: MOH; 2020. Avaliable from: http://www.moh. gov.my/index.php/pages/view/2019-ncov-wuhanguidelines.

28. Awadallah $M$, Idle $M$, Patel $K$, et al. Management update of potentially premalignant oral epithelial lesions. Oral Surg Oral Med Oral Pathol Oral Radiol 2018;125(6):628-636. DOI: 10.1016/j.00oo.2018. 03.010 .

29. Ilhan B, Epstein JB, Guneri P. Potentially premalignant disorder/lesion versus potentially premalignant patient. Relev Clin Care Oral Oncol 2019;92:57-58. DOI: 10.1016/j.oraloncology.2019.03.009.

30. Greenhalgh T, Wherton J, Shaw S, et al. Video consultations for COVID19. BMJ 2020;368:m998. DOI: 10.1136/bmj.m998.

31. Hollander JE, Carr BG. Virtually perfect? telemedicine for COVID-19. N Engl J Med 2020(18):(in press) 10.1056/NEJMp2003539.

32. Machado RA, de Souza NL, Oliveira RM, et al. Social media and telemedicine for oral diagnosis and counselling in the COVID-19 era. Oral Oncol 2020;105:104685. DOI: 10.1016/j.oraloncology.2020. 104685.

33. Ather A, Patel B, Ruparel NB, et al. Coronavirus disease 19 (COVID-19): implications for clinical dental care. JOE 2020;46(5):584-595. DOI: 10.1016/ j.joen.2020.03.008.

34. Mathur P. Hand hygiene: back to the basics of infection control. Indian J Med Res 2011;134(5):611-620. DOI: 10.4103/0971-5916.90985.
35. Day M. COVID-19: ibuprofen should not be used for managing symptoms, say doctors and scientists. BMJ 2020;368:m1086. DOI: 10.1136/bmj.m1086.

36. Samaranayake LP, Peiris M. Severe acute respiratory syndrome and dentistry. JADA 2004;135(9):1292-1303. DOI: 10.14219/jada. archive.2004.0405.

37. Ahmad IA. Rubber dam usage for endodontic treatment: a review. Int Endod J 2009;42(11):963-972. DOI: 10.1111/j.1365-2591.2009.01623.x.

38. Cochran MA, Miller $\mathrm{CH}$, Sheldrake MA. The efficacy of the rubber dam as a barrier to the spread of microorganisms during dental treatment. J Am Dent Assoc 1989;119(1):141-144. DOI: 10.14219/jada. archive.1989.0131.

39. Samaranayake LP, Reid J, Evans D. The efficacy of rubber dam isolation in reducing atmospheric bacterial contamination. ASDC J Dent Child 1989;56(6):442-444.

40. Meng L, Hua F, Bian Z. Coronavirus disease 2019 (COVID-19): emerging and future challenges for dental and oral medicine. J Dent Res 2020(5). DOI: $10.1177 / 0022034520914246$.

41. Liu Z, Zhang $Y$, Wang $X$, et al. Recommendations for surgery during the novel coronavirus (COVID-19) epidemic. Indian J Surg 2020(2):1-5. DOI: 10.1007/s12262-020-02173-3.

42. Eggers $M$, Torsten $\mathrm{K}-\mathrm{J}$, Eickmann $\mathrm{M}$, et al. In vitro bactericidal and virucidal efficacy of povidone-iodine gargle/mouthwash against respiratory and oral tract pathogens. Infect Dis Ther 2018;7(2):249259. DOI: 10.1007/s40121-018-0200-7.

43. Agrawal S, Goel AD, Gupta N. Emerging prophylaxis strategies against COVID-19. Monal Arch Chest Dis 2020;90(1289):169-172. 